\title{
Impact of nano silica on strength and durability properties of self- compacting concrete
}

\author{
Kiran Kumar Poloju*, Vineetha Anil, Ram Kishore Manchiryal
}

Department of Civil Engineering, Middle East College, Muscat, Oman

\section{A R T I C LE IN F O}

\section{Article history:}

Received 25 January 2017

Received in revised form

4 April 2017

Accepted 13 April 2017

\section{Keywords:}

Self-compacting concrete (SCC)

Nano silica

\begin{abstract}
A B S T R A C T
This paper reflects self-compacting concrete which is developed using modified Nan-Su mix design. Slump flow, J-Ring, V-funnel tests are conducted to justify the fresh properties of SCC and are checked. Cubes of $150 \times 150 \times 150 \mathrm{~mm}$ size casted in which 15 cubes are SCC without Nano silica and 15 cubes are of each $1 \%, 1.5 \%$ and $2 \%$ of Nano silica (colloidal state with $16 \%$ and $30 \%$ Nano content). In order to get relative idea about the compressive strength and durability properties of SCC, axial compression test on cubes for 7 days and 28days of curing in water were done and also cubes were immersed in $5 \% \mathrm{HCl}$ and $5 \% \mathrm{H}_{2} \mathrm{SO}_{4}$ respectively. Sorptivity test has also been conducted to assess durability of SCC. Test results indicate that use of Nano Silica in SCC has improved the performance of SCC in strength as well as in durability.
\end{abstract}

(C) 2017 The Authors. Published by IASE. This is an open access article under the CC BY-NC-ND license (http://creativecommons.org/licenses/by-nc-nd/4.0/).

\section{Introduction}

Self-Compacting Concrete (SCC) is considered as a new generation of concrete, which has generated tremendous interest in construction industry .SCC was first introduced in late 1980's by Japanese Researcher to reach durable concrete structures. According to Okamura and Ouchi (2003) SCC can be compacted into every corner of a formwork by means of its own weight. Okamura in 1986 started a research project on the flowing ability and workability of this special type of concrete, later called SSC. In 1989, Ozawa et al. (1989) succeeded in developing SCC for the first time. The year after that, an open experiment on the new type of concrete was held at the University of Tokyo, in front of more than 100 researchers and engineers. As a result, intensive research has begun in many places, especially in the research institutes of large construction companies and the University of Tokyo.

Even with difficult casting conditions SCC can be used for placing in congested reinforced concrete structures. It ensures proper filling and good structural performance of heavily reinforced structural members, for such applications, the fresh concrete must possess high fluidity and at the same

\footnotetext{
* Corresponding Author.

Email Address: kpoloju@mec.edu.om (K. K. Poloju) https://doi.org/10.21833/ijaas.2017.05.021

2313-626X/C) 2017 The Authors. Published by IASE.

This is an open access article under the CC BY-NC-ND license

(http://creativecommons.org/licenses/by-nc-nd/4.0/)
}

time, cohesive enough to be handled without segregation or bleeding.

SCC development is a desirable achievement in the construction industry in order to overcome problems associated with cast-in-place concrete. The other advantages of SCC are:

- Not affected by the skills of workers.

- The shape and amount of reinforcing bars or the arrangement of a structure.

- It can be pumped longer distances.

- Shorten construction period.

- Assures compaction in the structures especially in the confined zones where vibration and compaction is difficult.

- It provides high stability during transport and placement.

- It provides uniform surface quality and homogenous.

- It provides greater freedom for design.

- It is useful for casting of underwater structures.

\subsection{Nano materials}

The Nano materials can improve vital characteristics of construction materials such as strength, durability, and lightness, endow useful properties (e.g., heat-insulating, self-cleaning, and antifogging), and function as key sensing components to monitor construction safety and structural health. 


\subsection{Nano-silica}

The particle packing in concrete can be improved by using Nano-silica which leads to densifying of the micro and nanostructure resulting in improved mechanical properties. Li et al. (2004) studied the effect of nano silica addition on concrete water permeability and microstructure Different concrete mixes were evaluated incorporating nano silica particles of 10 to $20 \mathrm{~nm}$ (s.s.a. of $160 \mathrm{~m}^{2} / \mathrm{g}$ ), fly ash, gravel and plasticizer to obtain the same slump time as for normal concrete and nano silica concrete. The test results show that nano silica can improve the microstructure and reduce the water permeability of hardened concrete. Ji demonstrated that nano silica can react with $\mathrm{Ca}(\mathrm{OH})_{2}$ crystals, and reduce the size and amount of them, thus making the interfacial transition zone (ITZ) of aggregates and binding cement paste denser. The nano silica particles fill the voids of the CSH-gel structure and act as nucleus to tightly bond with C-S-H-gel particles. This means that nano silica application reduces the calcium leaching rate of cement pastes and therefore increasing their durability.

Nano-silica addition to cement based materials can also control the degradation of the fundamental C-S-H (calcium-silicate-hydrate) reaction of concrete caused by calcium leaching in water as well as block water penetration and therefore lead to improvements in durability.

Nano-Silica (NS) is the first nano product that replaced the micro silica. It has a specific surface area near to $1,00,000 \mathrm{~m}^{2} / \mathrm{kg}$ (micro silica has only $20,000 \mathrm{~m}^{2} / \mathrm{kg}$ ) and a particle size of $5 \mathrm{~nm}$ to $250 \mathrm{~nm}$. Nano Silica (NS) can contribute to efficient 'Particle Packing' in concretes by densifying the micro and nanostructure leading to improved mechanical and durability properties.

As the strength and behaviour of SCC is a function of the aggregate characteristics and mineral as well as chemical admixture content, there is a need to reinvestigate proportion of mineral and chemical admixtures that would result in optimized performance of SCC. The combined use of cement, nano silica (NS), and superplasticiser (SP) on durability of SCC is assessed by conducting, water absorption, sorptivity and immersion in acid (5\% $\mathrm{HCl}$ and $\mathrm{H}_{2} \mathrm{SO}_{4}$ ) test (EFNARC, 2005). Their research work presents the results of a comparative study of the sorptivity, accomplished in mixtures of SSC with different types of additions and a normal concrete compacted by vibration. The study of Bassuoni and Nehdi (2009), aimed at investigating the resistance of a variable range of SCC mixture designs to sulphuric acid attack.

\section{Experimental investigation}

\subsection{Materials used}

The different materials used in this investigation are:
- Cement: the cement used in present work is 53 grade cement confirming to IS: 12269 . The specific gravity of cement used is 3.10 .The cement produced from, the same constituent has been throughout the experimental program. The initial setting time is $30 \mathrm{~min}$.

- Fine aggregate: river sand and local sand confirming to IS 383, Zone 2 sand has been used in this experimental program. Specific gravity of fine aggregate is 2.62 .

- Coarse aggregate: machine crushed granite confirming IS 383 and IS 2386, has been used in this experimental program. Specific gravity of coarse aggregate is 2.82 .

- Water: potable water is used in this investigation.

- Chemical admixture (conplast SP430): high range water reducing admixtures known as super plasticizers are used for improving or workability for decreased water-cement ratio without decreasing the compressive strength. Conplast SP430 combines the properties of water reduction and workability retention. It allows the production of high performance concrete and/or concrete with high workability.

- Fly ash: fly ash confirming to IS 3812:1981 is used as mineral admixture. Mineral admixtures are used to improve the fresh and hardened properties of concrete and at the same time reduce the cost of concrete materials. In order to achieve the necessary viscosity to avoid segregation, additional fine materials are used.

\subsection{Properties of nano-sioz}

In this study, two different types of suspended nano silica gel containing different percentages of active nano silica with $99.99 \%$ pure $\mathrm{SiO}_{2}$ is used. The nomenclature followed for different nano silica gel is given in Table 1.

Specific gravity of each material varies from 1.08 to 1.32. Particle size of nano Silica varies between 5$40 \mathrm{~nm}$. The $\mathrm{pH}$ of the solutions is between 9.3 and 10.4. The properties of different nano silica provided by the manufacturer are given in Table 1 .

\section{Introduction to experimental study}

The experimental study consists of arriving at suitable mix proportions that satisfied the fresh properties of SSC as per EFNARC (2002) specifications. Standard cube moulds of $150 \mathrm{~mm} \mathrm{x}$ $150 \mathrm{~mm} \times 150 \mathrm{~mm}$ made of cast iron were used for casting standard cubes.

The standard moulds were fitted such that there are no gaps between the plates of the moulds. If there are any small gaps they were filled with plaster of paris. The moulds were then oiled and kept ready for casting. After $24 \mathrm{hrs}$ of casting, specimens were demoulded and transferred to curing tank wherein they were immersed in water for the desired period of curing. The Table 2 gives the details of the specimens used for the experimental study. 


\subsection{Mix design proportions}

The Mix design is prepared for M40 grade of concrete for the experimental program and shown in the Table 3 .

\subsection{Acid attack study}

An experiment was conducted on SCC with and without nano silica additions. Specimens were immersed in $5 \%$ solution of $\mathrm{H}_{2} \mathrm{SO}_{4}$ and $5 \%$ solution of $\mathrm{HCl}$. These specimens were placed in plastic tub such a way that the clearance around and above the specimens is more than or equal to $30 \mathrm{~mm}$. After an interval of 7 days measurements were taken and the solution has been changed. Once the specimen has been removed for testing from the plastic tub, each specimen is brushed with soft nylon brush and rinsed in tap water. The response of the specimen after immersing in the solution was evaluated through change in compressive strength, weight, appearance, thickness and solid diagonals. For determining the resistance of concrete specimens to aggressive environment such as acid attack, the durability factors are proposed by the author, as described in ASTM C 666 - 1997, as the basis. ASTM C 666 - 1997 gives the standard test method for resistance of concrete to rapid freezing and thawing and the durability factors.

Table 1: Properties of nano-sio2

\begin{tabular}{cccc}
\hline Notation for Nano Silica Gel & Active nano content $(\% \mathrm{wt} / \mathrm{wt})$ & $\mathrm{pH}$ & Specific gravity \\
\hline XLP & 16.0 & $9.3-9.6$ & $1.08-1.11$ \\
XTX & 30.0 & $9.0-10.0$ & $1.20-1.22$ \\
\hline
\end{tabular}

Table 2: Details of specimens cast

\begin{tabular}{|c|c|c|c|c|c|c|c|}
\hline \multicolumn{3}{|c|}{ SCC with NS ( $30 \%$ Nano content) } & \multicolumn{3}{|c|}{ SCC with NS (16\% Nano content) } & \multirow[t]{2}{*}{ SCC (without NS) } & \multirow{2}{*}{$\begin{array}{c}\text { Type of Concrete } \\
\begin{array}{c}\% \text { of NS added by BWOC } \\
\text { added }\end{array}\end{array}$} \\
\hline $2 \%$ & $1.50 \%$ & $1 \%$ & $2 \%$ & $1.50 \%$ & $1 \%$ & & \\
\hline 15 & 15 & 15 & 15 & 15 & 15 & 15 & No. of cubes cast \\
\hline
\end{tabular}

Table 3: Mix proportion

\begin{tabular}{|c|c|c|c|c|c|c|c|}
\hline Mix & $\begin{array}{c}\text { Cement } \\
(\mathrm{kg} / \mathrm{m} 3)\end{array}$ & $\begin{array}{c}\text { Fly ash } \\
(\mathrm{kg} / \mathrm{m} 3)\end{array}$ & $\begin{array}{c}\text { F.A } \\
(\mathrm{kg} / \mathrm{m} 3)\end{array}$ & $\begin{array}{c}\text { C.A } \\
(\mathrm{kg} / \mathrm{m} 3)\end{array}$ & $\begin{array}{c}\text { SP } 430 \\
\text { ((lit/m3) }\end{array}$ & $\begin{array}{c}\text { Water } \\
\text { (lit/m3) }\end{array}$ & $\begin{array}{c}\text { NS(colloidal) } \\
(\mathrm{kg} / \mathrm{m} 3)\end{array}$ \\
\hline Normal SCC & 468 & 353.05 & 946.72 & 794.48 & 19.7 & 244.71 & - \\
\hline NS.XLP (1\%) & 468 & 353.05 & 946.72 & 794.48 & 19.7 & 220.14 & 29.25 \\
\hline NS.XLP (1.5\%) & 468 & 353.05 & 946.72 & 794.48 & 19.7 & 207.86 & 43.87 \\
\hline NS.XLP (2\%) & 468 & 353.05 & 946.72 & 794.48 & 19.7 & 195.60 & 58.50 \\
\hline NS.XTX (1\%) & 468 & 353.05 & 946.72 & 794.48 & 19.7 & 229.11 & 15.60 \\
\hline NS.XTX(1.5\%) & 468 & 353.05 & 946.72 & 794.48 & 19.7 & 233.79 & 23.40 \\
\hline NS.XTX (2\%) & 468 & 353.05 & 946.72 & 794.48 & 19.7 & 222.87 & 31.20 \\
\hline
\end{tabular}

In the present investigation, the author derived the "Acid Durability Factors" directly in terms of relative strengths. The relative strengths are always with respect to the 28 days value (i.e. at the start of the test). The "Acid Durability Factors" (ADF) can be designed as follows:

\section{Acid Durability Factor $(A D F)=\operatorname{Sr} N / M$}

Where,

$\mathrm{Sr}=$ relative strength at $\mathrm{N}$ days, (\%)

$\mathrm{N}=$ number of days at which the durability

factor is needed.

$\mathrm{M}=$ number of days at which the exposure is to be terminated. Acid attack test was terminated at 28 days.

\section{So, $\mathrm{M}$ is 28 in this case.}

The extent of deterioration at each corner of the struck face and the opposite face is measured in terms of the solid diagonals (in $\mathrm{mm}$ ) for each of two cubes and the "Acid Attack Factor" (AAF) per face is calculated as follows:

$A A F=$ (Loss in mm on eight corners of each of 2 cubes) $/ 4$
The percentage weight loss and strength loss at $3,7,14,21,28$ days.

\subsection{Sorptivity study}

The sorptivity tests were carried out on all batches of SCC with size of $15 \times 15 \times 15 \mathrm{~cm}$, These specimens were kept in the oven for drying at a temperature $100{ }^{\circ} \mathrm{C}$, it was stored until there was negligible weight loss. The test specimens were weighed and recorded before placing them in the recipient. Afterwards the specimens were placed in the recipient in contact with water level capable to submerge them about $5 \mathrm{~mm}$.After definite interval of time the specimens were removed, weighed and measurements recorded. Again these specimens were placed in the recipient for definite intervals of time and repeated for $15 \mathrm{~min}, 30 \mathrm{~min}, 1$ hour, 2 hour, 4 hours. 6 hours, 24 hours, 72 hours, 7 days, 14 days and 28 days.

Because of a small initial surface tension and buoyancy effects, the relationship between cumulative water absorption $\left(\mathrm{kg} / \mathrm{m}^{2}\right)$ and square root of exposure time $\left(\mathrm{t}^{0.5}\right)$ shows deviation from linearity during first few minutes. Thus, for the calculation of sorptivity coefficient, only the section of the curves for exposure period from $15 \mathrm{~min}$ to 72 
hrs, where the curves were consistently linear, was used.

The sorptivity coefficient $(\mathrm{k})$ was obtained by using the following expression:

$\frac{W}{A}=k \sqrt{t}$

Where,

$W=$ the amount of water adsorbed in (kg);

$A=$ the cross-section of specimen that was in contact with water $\left(\mathrm{m}^{2}\right)$;

$t=$ time $(\min )$;

$k=$ the sorptivity coefficient of the specimen $\left(\mathrm{kg} / \mathrm{m}^{2} / \min ^{0.5}\right)$.

\section{Discussion of test result}

The results of various strength and durability tests are described here.

\subsection{Effect of nano silica on compressive strength}

Fig. 1 shows the details of Compressive Strength of SCC with and without nano silica. It is very much evident from the figure that there is only a steep increase in the compressive strength of SCC with nano silica concrete than without nanosilica. It can also be said that nano silica with $1.5 \%$ addition is optimum in both the grades of nano silica. Compressive strength of NS-XLP of $1.5 \%$ bwoc added in SCC is more compared to NS-XTX of $1.5 \%$ bwoc.

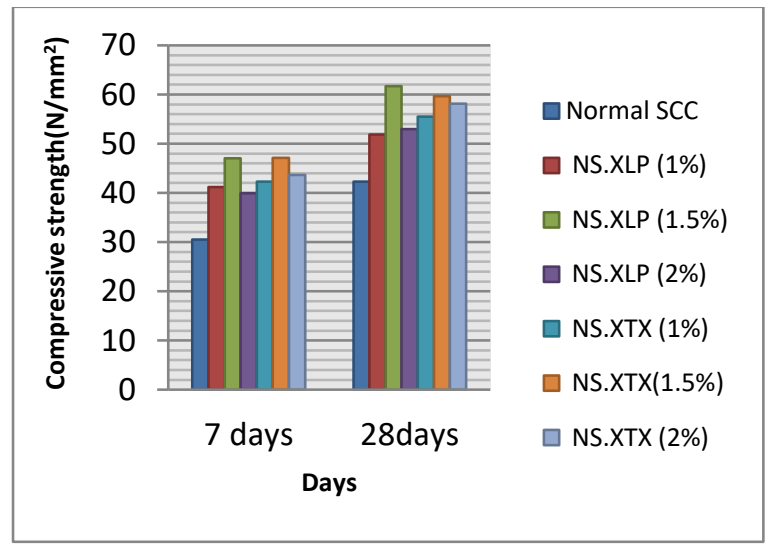

Fig. 1: Average compressive strength of SCC without and with nano silica

\subsection{Acid attack}

To study the resistance of with and without nano silica SCC, specimens were cured for 28 days and then immersed in $5 \%$ of $\mathrm{H}_{2} \mathrm{SO}_{4}$ and HCL respectively. This is the idea to test the influence of acids $\left(\mathrm{H}_{2} \mathrm{SO}_{4} \&\right.$ HCL) concrete. 12 cube specimens of $150 * 150 * 150 \mathrm{~mm}$ were immersed in a tub. These tubs were kept covered throughout the tests to minimize the loss of evaporation. The chemical resistance was calculated by weight loss and compressive strength loss of the specimens. At the end of 7, 14, 21 and 28 days the weight loss is given by (W2-W1)/W1 * 100 where, W1 and W2 are weights of specimen (in grams) before and after the immersion of specimens in acid. In acid attack studies on nano silica additions in SCC, the effect of $5 \% \mathrm{H}_{2} \mathrm{SO}_{4}$ and $5 \% \mathrm{HCl}$ acid were studied. The various observations made are explained below.

\subsubsection{Change in mass}

The change in the mass of the specimens were observed and plotted against the number of immersion days in acids as shown in the following Figs. 2 and 3.

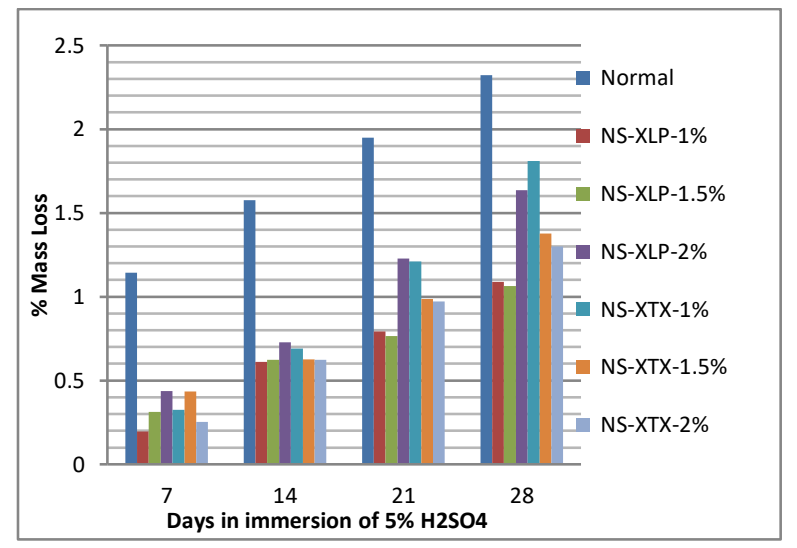

Fig. 2: $\%$ mass loss when immersed in $5 \% \mathrm{H}_{2} \mathrm{SO}_{4}$

From the Fig. 2 it can be observed that specimens immersed in $5 \% \mathrm{H}_{2} \mathrm{SO}_{4}$ for 28 days that the percentage of mass loss in normal SCC is more when compared to various percentages of nano silica additions.

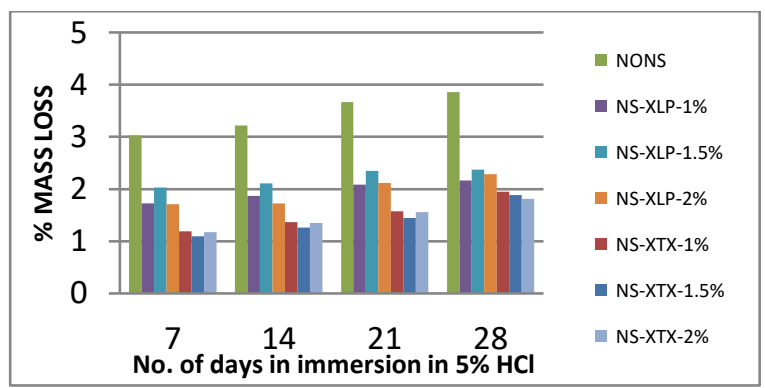

Fig. 3: \% mass loss when immersed in 5\% $\mathrm{Hcl}$

From Fig. 3 it can be observed that the mass loss in normal SCC is more when compared to various percentages of nano silica addition. After 28 days of immersion Nano silica-XTX $2 \%$ has less percentage of mass loss in Hydrochloric acid.

\subsubsection{Acid durability factor}

The \% loss of Compressive Strength and Acid Durability Factor (ADF) of the specimens were observed and plotted against the number of immersion days in acids as shown in the following Figs. 4, 5, 6 and 7.

From the Figs. 4, 5, 6 and 7 From the figures, the following observation are made: 
i. After 28 days of immersion in both the acid solutions percentage loss of compressive strength of $1.5 \%$ Nano-XLP SCC is more when compared due to normal SCC.

ii. Acid durability factor for cube immersed in $5 \%$ sulphuric acid is more for $1 \%$ Nano silica SCC of two grades. This implies that $1 \%$ addition is more durable when compared to other.

iii. Acid durability factor for cube immersed in 5\% Hydrochloric acid is almost same for all the specimens and but it is more for 2\% Nano silica XTX grade, also for $1 \%$ Nano silica SCC of two grades . This implies that $2 \%$ Nano silica SCC of XTX grade, $1 \%$ addition of both grades of nano silica is more durable in hydrochloric acid when compared to other.

It is observed that the percentage loss of compressive strength is more in sulphuric acid is more when compared to hydrochloric acid.

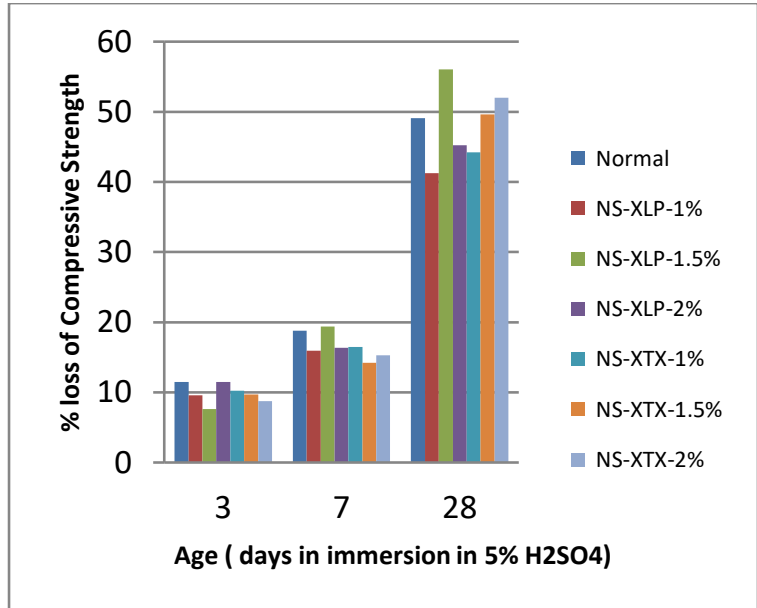

Fig. 4: \% loss of Compressive Strength for cubes immersed in $5 \% \mathrm{H}_{2} \mathrm{SO}_{4}$

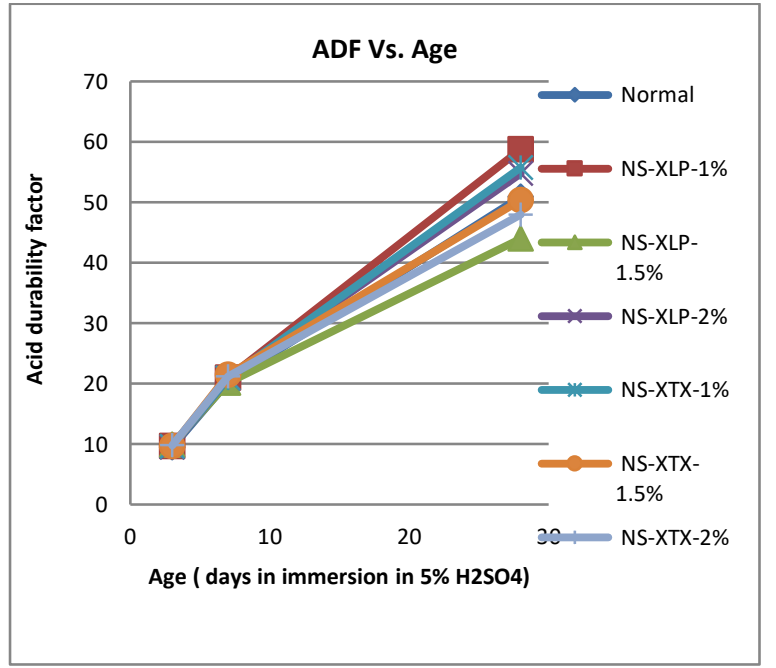

Fig. 5: Graph between Acid Durability Factor and No. of days in immersion in $5 \% \mathrm{H}_{2} \mathrm{SO}_{4}$

\subsubsection{Acid attack factor}

The Acid Attack Factor (AAF) of the specimens were observed and plotted against the number of immersion days in acids as shown in the following Figs. 8 and 9.

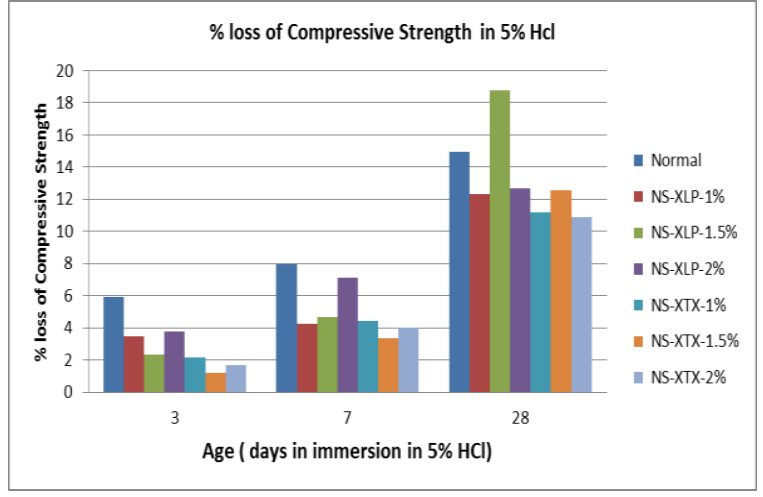

Fig. 6:\% loss of Compressive Strength for cubes immersed in $5 \% \mathrm{Hcl}$

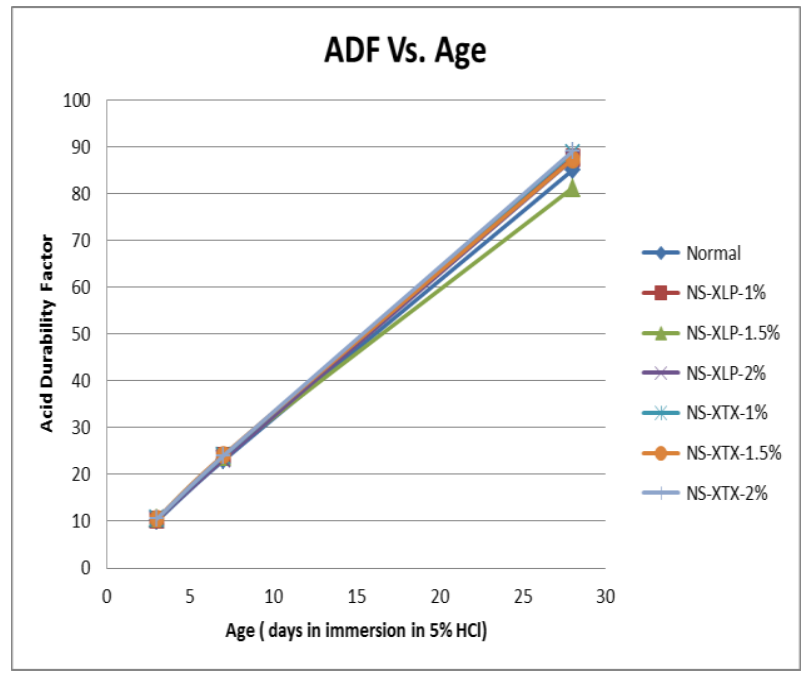

Fig. 7: Graph between Acid Durability Factor and No. of days in immersion in $5 \% \mathrm{Hcl}$

From the figures, the following observations are made:

i. After 28 days immersion in sulphuric acid solution of the specimen, the loss of diagonal lengths is more in SCC without nano silica when compared to nano additions.

ii. After 28days of immersion of the specimen in sulphuric acid solution, $1 \%$ and $1.5 \%$ Nano silicaXLP is less attacked when compared to other nano percentages and normal SCC in terms of Acid attack factor.

iii. Nano silica additions are less attacked and said to be more durable when compared with normal SCC in terms of Acid attack factor.

iv. Acid Attack factor for cube immersed in 5\% sulphuric acid is more when compared with solutions of 5\% Hydrochloric acid.

v. AAF values are almost same for the cubes immersed in $5 \% \mathrm{HCl}$ after 28 days.

\subsubsection{Sorptivity}

In the present investigation sorptivity tests were conducted on cube specimens of size $150 * 150 * 150 \mathrm{~mm}$. The weight recorded at the end of different intervals is noted down and sorptivity is calculated. The result can be observed from Fig. 10.

A general observation from figure is that sorptivity decreases with addition of nano silica 
when compared with normal SCC. This shows nanoadditions are better than SCC.

Acid Attack Factor for cubes immersed in $5 \% \mathrm{H} 2 \mathrm{SO} 4$

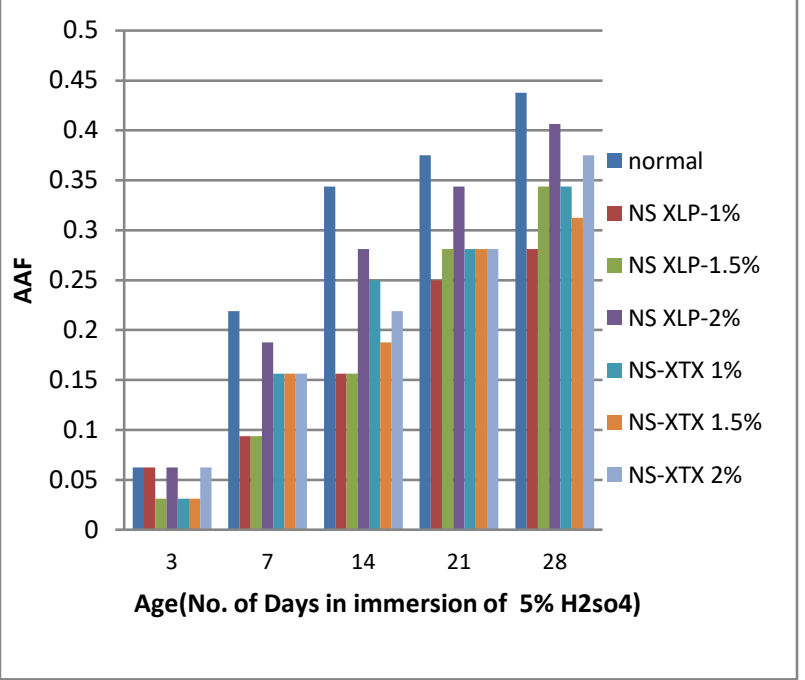

Fig. 8: Bar chart showing Acid Attack Factor of cubes immersed in $5 \% \mathrm{H}_{2} \mathrm{SO}_{4}$

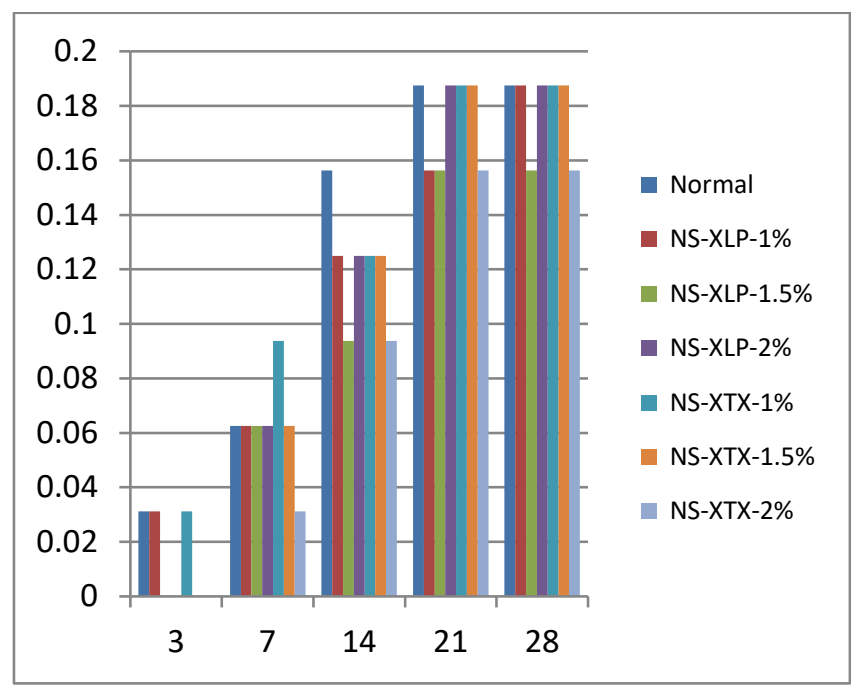

Fig 9: Bar chart showing Acid Attack Factor for cubes immersed in $5 \% \mathrm{HCl}$

\section{Conclusion}

The present work deals with effect of nano silica additions on strength and durability properties on Self compacting concrete. The conclusions obtained from the study are:

1. There is a steep increase in the compressive strength at 28days of about $45.2 \%$ and $41.13 \%$ with the addition of $1.5 \%$ Nano silica of XLP grade and XTX grade respectively. Hence $1.5 \%$ addition of nano silica is said to be optimum.

2. After 28 days, the percentage mass loss for Nano Silica XLP with $1.5 \%$ addition is $1.06 \%$ in $5 \%$ sulphuric acid, which is said to be less when compared to other percentage of nano silica.

3. After 28 days, the percentage mass loss for Nano Silica XTX with $2 \%$ addition is $1.81 \%$ in $5 \%$ hydrochloric acid, which is said to be less when compared to other percentage of nano silica.

4. The percentage compressive strength loss is more for 1.5\% Nano Silica-XLP and is about $56.02 \%$ and $18.74 \%$ with 5\% $\mathrm{H} 2 \mathrm{SO} 4$ and 5\% $\mathrm{HCl}$ respectively after 28 days of immersion. This may be due to higher pozzalonic content.

5. At 28 days, the loss of compressive strength is less for XLP- Nano-Silica of $1 \%$ addition which is about $41.23 \%$ and has more Acid Durability factor of about 58.77 in sulphuric acid, hence it is said to be more durable when compared to other nano additions.

6. Acid durability factor for cubes immersed in 5\% Hydrochloric acid are almost same but after 28 days ADF is more for 2\% Nano silica SCC of XTX grade, and also for $1 \%$ Nano silica SCC of two grades. This implies that 2\% Nano silica SCC of XTX grade, $1 \%$ addition is more durable in hydrochloric acid when compared to other in terms of Acid durability factor.

7. Nano silica additions are less acid attacked and said to be more durable when compared with SCC without nano silica in terms of Acid attack factor.

8. Nano silica additions in SCC are almost impermeable, as there is no capillary suction. This might be due to the filling of nano materials into the pores.

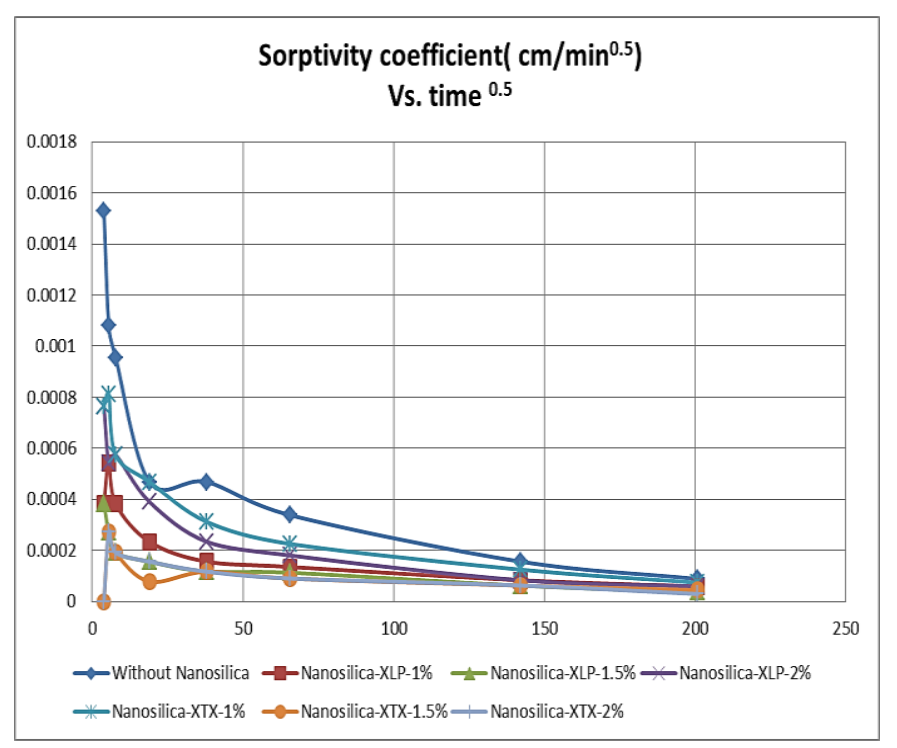

Fig. 10: Sorptivity of the cubes immersed up to $10 \mathrm{~mm}$ in water

Hence, it can be concluded that nano silica additions in SCC is good enough to satisfy the requirements for compressive strength, durability and sorptivity. But it has failed in satisfying durability requirements.

\section{References}

Bassuoni MT and Nehdi ML (2009). Durability of selfconsolidating concrete to different exposure regimes of sodium sulfate attack. Materials and Structures, 42(8): 10391057. 
EFNARC (2002). Specifications and guidelines for self-compacting concrete. European Federation of National Associations Representing for Concrete, Surrye, UK.

EFNARC (2005). Specifications and guidelines for self-compacting concrete. European Federation of National Associations Representing for Concrete, Surrye, UK.

Li H, Xiao HG, Yuan J, and Ou J (2004). Microstructure of cement mortar with nano-particles. Composites Part B: Engineering 35(2): 185-189.
Okamura H and Ouchi M (2003). Self-compacting concrete. Journal of Advanced Concrete Technology, 1(1): 5-15.

Ozawa K, Kunishima M, Maekawa K, and Okamura H (1989). Development of high performance concrete based on the durability design of concrete structures. In the $2^{\text {nd }}$ Conference on East-Asia and Pacific Structural Engineering and Construction (EASEC'89), Chiang Mai, Thailand, 1: 445-450. 